\title{
The hematopoietic stroma
}

N.B. Nardi and Z.Z.C. Alfonso

\author{
Departamento de Genética, \\ Universidade Federal do Rio Grande do Sul, \\ Porto Alegre, RS, Brasil
}

\begin{abstract}
Correspondence
N.B. Nardi

Departamento de Genética, UFRGS

Av. Bento Gonçalves, 9500

Caixa Postal 15053

91501-970 Porto Alegre, RS

Brasil

Fax: + 55-51-319-2011

E-mail: nardi@vortex.ufrgs.br

Presented at the 5th Brazilian

Symposium on Extracellular

Matrix - SIMEC, Angra dos Reis,

RJ, Brasil, September 7-10, 1998.

Publication supported by FINEP.

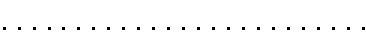

Received December 3, 1998

Accepted January 11, 1999
\end{abstract}

\section{Abstract}

All blood cells are derived from a small common pool of totipotent cells, called hematopoietic stem cells. The process is strictly regulated by the hematopoietic microenvironment, which includes stromal cells, extracellular matrix molecules and soluble regulatory factors. Several experimental in vitro assays have been developed for the study of hematopoietic differentiation, and have provided valuable information on the stroma, which includes, among other cell types, macrophages, fibroblasts, adipocytes, and endothelial cells. The composition, ontogeny, and function in physiological as well as pathological conditions of stroma are discussed.

\section{The hematopoietic system}

Blood cells composing the hematopoietic system can be classified into two main classes, i.e., lymphoid (B, T and natural killer lymphocytes) and myeloid (erythrocytes, megakaryocytes, granulocytes and monocytes). The life span of the fully differentiated mature forms of blood cells may vary considerably, being of the order of several hours for some cells (granulocytes), and several weeks (erythrocytes) to several years (memory cells) for others. This system is extraordinarily complex, since not only huge numbers of new mature cells are produced per day (about 1 trillion cells, including 200 billion erythrocytes and 70 billion neutrophilic leukocytes, in a 70-kg man), but there is also a need for the maintenance of a pool of undifferentiated cells and for a rapid response to situations of acute stress (1).

Increased production of cells is largely restricted to the specific cell type that is required in the particular stress situation: hemolysis, for example, induces erythroid hyperplasia, while granulocyte hyperplasia is observed in response to bacterial infections. Alterations in the balance between self-renewal and differentiation can lead to the emergence of cells that survive and grow in situations unfavorable to the growth of normal cells and hence to the establishment of leukemias.

During ontogeny, there are a number of hematopoietic sites. Studies in mice and birds have shown that an early intra-embryonic site of hematopoiesis is found in the paraaortic splanchnopleura (2) and the aorta, gonads, and mesonephros or AGM (3). It is believed that hematopoietic stem cells arise in these two structures and in blood islands of the yolk sac, enter the embryonic circulation and colonize the newly formed liver rudiment. The fetal liver is the site of definitive hematopoiesis early during embryonal development. At birth, and throughout adult life, the bone marrow with its intersinusoidal spaces is the site responsible for the generation of blood cells. The mechanisms responsible for these ontogenic shifts are not well 
known, and may involve changes in the developing hematopoietic cells (4), or in the hematopoietic microenvironment $(5,6)$.

\section{D ifferentiation in the hematopoietic system}

All different types of blood cells are derived, through a series of maturational cell divisions regulated by the hematopoietic microenvironment, from a small common pool of totipotent cells called hematopoietic stem cells. The stem cell concept originated from the work of Till and McCulloch in 1961 (7), showing the formation of nodules of hematopoietic cells in the spleens of lethally irradiated mice after reconstitution with bone marrow from normal syngeneic donors. In spite of much effort since then, stem cells are still elusive entities, as illustrated by some of the reports available in the literature ("What defines a pluripotent hematopoietic stem cell (PHSC): will the real PHSC please stand up!" (8), "In search of the hemopoietic stem cell" (9) or "Which are the hematopoietic stem cells? (or: Don't debunk the history!)" (10)).

These cells are of interest not only because of their developmental capacity but also because of their potential usefulness for the treatment of hematological disorders and as vectors for gene therapy. The most widely used criterion for their identification, that of a multipotential cell capable of self-renewal as well as of reconstituting long-term hematopoiesis after marrow ablation, presents theoretical as well as practical problems (11). Besides these two main characteristics, other well-established features of human stem cells include (12): a) They constitute a very small compartment, with estimates varying from less than $0.05 \%$ to up to $0.5 \%$ of cells in the bone marrow. b) The majority of stem cells are normally quiescent, as shown by their resistance to treatment with 5-fluorouracil or 4-hydroperoxycyclophosphamide, which spare them and eliminate dividing cells with- out adversely affecting the long-term repopulating ability of bone marrow. Estimates of periodicity of mitosis vary widely (once a month to once in a few years), and the direct examination of the cell cycle of long-term cells indicates that at any moment only $4 \%$ of them are in the $S / \mathrm{G}_{2} / \mathrm{M}$ phases. c) Their surface phenotype is poorly known, and includes the presence of CD34 and the absence of CD38, HLA-DR and other lineage markers. d) Besides bone marrow, they can be found in umbilical cord blood and in peripheral blood, particularly after "mobilization" treatments.

When stem cells divide, they may return to the $\mathrm{G}_{0}$ phase of the cell cycle generating more stem cells; alternatively, they may generate large numbers of committed progenitors with a progressively restricted differentiation potential. The mechanisms involved in the process of self-renewal versus differentiation of the stem cell at each division are poorly known $(1,11)$. Recent progress has been made with the identification of homeotic genes that appear to be of fundamental importance in these and other cellular processes (13).

Most models assume that the self-renewal potential of stem cells is finite, as evidenced by serial transfer experiments (14) and supported by the "Hayflick limit" concept (15). Stochastic and deterministic models (reviewed in 12) attribute different weights to the roles played by intrinsic and microenvironmental factors in the decision of selfrenewal or differentiation.

The transition from stem cells to mature hematopoietic cells occurs through several intermediate steps characterized by the progressive loss of the self-renewal capacity and the commitment to a specific cell lineage. The progenitor cell compartment, which can be identified by the expression of specific lineage markers, comprises cell types which are determined to differentiate into any of the hematopoietic lineages. The developmental potential of these cells is gener- 
ally limited to only one or two of the hematopoietic lineages, and these cells progressively display the antigenic, biochemical, and morphological features characteristic of the mature cells of the appropriate lineages, losing their capacity for self-renewal. Their proliferation is normally tightly controlled and coupled to development, so that cells leaving the bone marrow usually possess little or no proliferative potential.

The expression of different receptors on the surface of hematopoietic progenitors permits the interaction with various regulatory elements present in their environment, which includes stromal cells, extracellular matrix molecules (ECM) and soluble regulatory factors (cytokines and growth/differentiation factors). Although the role played by the microenvironment in the determination of the stem cell fate is still unclear, its pivotal role in the regulation of the amplification of the progenitor cell compartment is well established. Further differentiation of cells into one of several lineages critically depends on the nature of factors acting on these cells at a particular time and at a particular concentration.

\section{The experimental analysis of hematopoietic differentiation}

Although histologic observations of the hematopoietic system continue to be the primary source of information on the process of differentiation (16), experimental assays have been fruitfully employed in the study of this system. As different assays detect and analyze hematopoietic cell types specifically stimulated by the experimental conditions employed, and the correspondence among the assays is not always easily established, many different names are given to the cell types observed, as detailed below.

Till and McCulloch (7), as already mentioned, established in 1961 the first quantitative assay for cells with a radioprotective effect. Although it is now clear that these cells - denominated spleen colony-forming units or CFU-S - do not represent the more primitive stem cells, the assay is useful for the investigation of early events in hematopoiesis. In vivo assays developed more recently, in which human hematopoietic cells are engrafted in immunodeficient mice, have demonstrated the existence of human pluripotent cells either by limiting dilution analysis or by clonal integration of a retroviral marker gene (17-19). The term marrow repopulating ability, derived from in vivo studies, refers to primitive totipotent hematopoietic stem cells with self-renewal capacity that are capable of repopulating the bone marrow of lethally irradiated mice (20). Two different types of cells with marrow repopulating ability have been distinguished in the mouse. Initial engraftment (short-term repopulation) is due to CFU-S. Long-term engraftment is attributed to a different cell type but is possible only if the animals also receive short-term repopulating cells. A cell type which is more primitive than CFU-S (pre-CFU-S) is considered to be responsible for long-term marrow repopulating ability.

However, it was the development of in vitro cultivation systems for the study of hematopoiesis (reviewed in 21), which had its heyday between 1965 and the late 1970s, that allowed the identification and quantification of several different types of precursor cells. The colony formation assay (22) allows the enumeration of early progenitors capable to form colonies when cultured under appropriate conditions in semisolid medium. In this test, cells are grown in vitro in soft agar or other highly viscous media, containing, for example, methylcellulose, plasma gel or fibrin clots. These semisolid media reduce cell movement and allow individual cells to develop into cell clones that are identified as single clusters ( $<50$ cells) or colonies ( $>50$ cells) of differentiated cells after a culture period of 7 to 14 days. These colonies are the progeny of single cells called colony-forming cells (CFC) or colony-form- 
ing units (CFU), and the composition of the colonies determines which CFU is being assessed. Thus, CFU-blasts give rise to colonies composed of cells with blast-like morphology, CFU-GEMM corresponds to pluripotent progenitor cells identified by the production of multilineage colonies (granulocytes, erythrocytes, monocytes and megakaryocytes), CFU-meg is a more restricted progenitor giving origin to megakaryocyte colonies, and so on (21). This system has also allowed the identification of the high proliferative potential colony-forming cells (HPP-CFC), defined by their ability to form very large colonies ( $>5 \mathrm{~mm}$ in diameter) containing approximately 50,000 cells and including progenitor and mature hematopoietic cells of the granulocyte, macrophage, and megakaryocyte lineages. Cells that give rise to colonies smaller than $1 \mathrm{~mm}$, on the other hand, are usually referred to as low proliferative potential colony-forming cells (LPP-CFC). These primitive hematopoietic stem cells are considered to comprise cell types such as BFU-E (erythrocyte blast-forming unit) and $\mathrm{CFU}$ granulocytes and monocytes (CFU-GM) (20).

Another culture system currently used for the study of hematopoietic progenitors is the delta assay (23). This assay uses a shortterm suspension culture in which potentially colony-forming cells are grown first in liquid culture for one week and then replated onto semisolid medium. Numbers of colonies observed are considered as an indicator of the number of hematopoietic progenitors of an earlier stage than those normally obtained after 14 days of growth in semisolid medium.

The generation of hematopoietic colonies is absolutely dependent on the continuous presence of so-called colony-stimulating factors (CSF), and this system was the key to the original discovery and characterization of many of the hematopoietic growth factors (24). Colony formation assays, therefore, allow the study of the influences of given growth factors or cytokines on the determination of the lineage along which colony-forming cells differentiate. Growth factors are denominated according to the colonies originating under their influence M-CSF or GM-CSF, for instance, for factors inducing colonies composed of monocytes or granulocytes and monocytes, respectively.

Sustained production or self-renewal of clonogenic cells, however, has not been possible with standard semisolid culture systems. The long-term culture system (LTC), originally described by Dexter for murine cells (25) and later adapted for human cells $(26,27)$, makes use of a rich culture medium containing high concentrations of horse serum and hydrocortisone and lower incubation temperatures, which allows the selfrenewal of stem cells over a period of several months in the presence of a supportive microenvironment. The long-term culture of bone marrow cells employs primary adherent layers of stromal cells as an important source of cytokines and low molecular weight substances required for the controlled differentiation and proliferation of hematopoietic progenitor cells. Stromal cells provide a complex functional ECM allowing direct cell-tocell contacts between different cell types. These, either alone or in synergy with defined cytokines, can conserve primitive stem cells, induce early differentiation of a fraction of the primitive progenitors, and prevent their terminal differentiation.

A second type of widely used LTC is the Whitlock-Witte long-term bone marrow culture (28), initially developed for murine bone marrow to obtain stromal layers devoid of hematopoietic cells. It is a lymphoid culture system which uses a "poor" culture medium containing 5\% fetal calf serum without cortisone and permits the growth of freshly isolated bone marrow cells that form confluent adherent stromal cell layers within 2-3 weeks. Whitlock-Witte cultures can reconstitute the B-lymphocyte compartment in immune-compromised mice, but do not main- 
tain primitive multilineage hematopoietic precursors such as CFU-S (20).

In addition to CFU-S and HPP-CFC, pluripotent stem cells and early precursors can be identified by the LTC assays as cobblestone area-forming cells (CAFC; 29) and longterm culture-initiating cells (LTC-IC). Sophisticated analyses such as limiting dilution analysis are used for the quantification of these cells (30). However, even these culture systems are unable to maintain hematopoiesis indefinitely due to limiting culture conditions or, alternatively, to a natural process of senescence of the hematopoietic cells. More recent evidence involving the transduction of CFU cells and LTC-IC using retroviral vectors, indicate that the in vitro progenitor assays currently available measure functionally different, and presumably less quiescent, populations than the long-term repopulating stem cell (31).

\section{The hematopoietic stroma}

To obtain sustained hematopoiesis, primitive hematopoietic cells must interact with an adequate microenvironment, which includes, as already mentioned, stromal cells, ECM components and soluble regulatory factors (32). The experimental analysis of hematopoiesis, as described above, has provided much of the present knowledge on the role played by the stroma in the process.

The term "stromal cells" is used rather loosely and the true histogeneic origin of these mesenchyme-derived cells is still uncertain. Stromal cells, which mechanically support the differentiating hematopoietic cells, include among others macrophages, fibroblasts, adipocytes, and endothelial cells and are frequently defined as non-hematopoietic cells $(1,33)$. Adventitial reticular cells reside on the adluminal surface of venous endothelial cells, which branch through the medullary cavity, and appear to provide a reticular network that supports hematopoietic cells. Marrow adipocytes possess the mechanical function of controlling hematopoietic volume: impaired hematopoiesis is associated with increased accumulation of fat inclusions, whereas accelerated hematopoiesis is associated with loss of fat vacuoles and the provision of increased space for hematopoietic cells (34). Adipocytes may play an additional role in blood cell production as a reservoir for lipids needed in cell metabolism during proliferation. Macrophages and osteoclasts, cells derived from hematopoietic precursor cells and osteoblasts, may also play important roles in the hematopoietic microenvironment. Macrophages are important in the clean-up of ineffective erythropoiesis and in the removal of the nuclear pole, produced during the process. Stromal cells represent a highly dynamic structure which plays an active role in hematopoiesis by producing ECM components and both soluble and membrane-associated growth factors (35).

Stromal cells are rare in the marrow (approximately $0.125 \%$ of the marrow cellularity), and since in bone marrow suspensions they are mostly contained in tight aggregates, their analysis in freshly isolated material is difficult (36). Although adherent stromal cell layers in LTC, established by growing bone marrow cells over a period of several weeks, are considered to mimic many characteristics of the marrow microenvironment, it has not yet been established conclusively that these cultures encompass all types of stromal cells identified in vivo and that they retain all of their functional properties in vitro.

As the heterogeneous composition of the stroma makes it extremely difficult to analyze the role of individual cell types in hematopoietic development, numerous stromaderived cell lines have been established from bone marrow and a variety of other tissues, including spleen, thymus, and non-hematopoietic organs such as kidney, lung, skin, or mammary tumors. These studies have shown in vitro the heterogeneity and compartmen- 
talization of cell types already observed during the in situ study of bone marrow. In the analysis of 33 bone marrow stromal cell lines, for instance, lineage-restricted stimulatory activity and a reciprocal relationship between granulocyte and macrophage formation were observed (37). A more detailed characterization of stromal lines generally shows differences with respect to growth potential, cell surface markers and cytokine transcripts, secondary to the varying capacity to expand bone marrow or cord blood stem/progenitor cells $(38,39)$. The cell types which compose these heterogeneous populations are also being separately analyzed. In one study, three cell types could be grown separately in vitro, and were identified as macrophages, endothelial-like cells and myofibroblasts, with different potential for the support of hematopoietic cell growth (40).

Hematopoietic stromal precursors have been described, besides adult bone marrow, in fetal liver and fetal bone marrow, with reported differences in the anatomic and ultrastructural characteristics which, however, have not been clearly correlated to functional differences $(6,41,42)$. Several studies suggest that hematopoietic progenitors collected at one stage of ontogenetic development may not be able to interact with a microenvironment originating from cells at a different ontogenetic stage. The observation that fetal liver progenitors may not be capable of differentiating in an adult bone marrow microenvironment, for instance (43), may have important implications for fetal liver transplantation into postnatal recipients.

The ontogeny of stromal cells is currently very poorly understood. Based on the well-established generation of multiple mesenchymal cell types from bone marrow cells, the existence of stromal stem cells has been proposed (44). Besides gaps in our knowledge of the biology of these cell populations, much information at the molecular level is also lacking. At least 16 Hox genes and 5 genes with homeobox domains have already been identified, although their temporal expression has not yet been determined (45).

The transplantation capability of stromal cells is also a controversial subject. Some studies have indicated that the stroma of bone marrow receptors is developed from the host's precursor cells (46-48), whereas others show that stromal cells in LTC of transplanted patients progressively originate from the donor marrow (49), a situation also reported for human/sheep chimeric cultures (50). In an in vivo system, it has been reported that murine bone marrow mesenchymal precursor cells, expanded in culture, were detected in the bone, cartilage and lungs of recipient mice at 1 to 5 months after transplantation (51). Recently, the migration of bone marrow-derived cells to areas of induced muscular degeneration, followed by differentiation along the myogenic pathway and participation in the regeneration of damaged fibers, has been reported in mice (52).

Differently from hematopoietic cells, the existence of stromal precursors outside the bone marrow in adults is highly controversial, so that while some studies have detected their presence in peripheral blood (53$55)$, others have reported negative results $(56,57)$. The existence of stromal precursors in cord blood under normal conditions is the subject of intense discussion (58-62). A representative recent study (58), for instance, reports deficient myeloid progenitor cell growth in LTC of umbilical cord blood, suggesting that this is due to the impaired development of an adherent layer. Under special conditions, Ye et al. (59) and Nieda et al. (60) reported the establishment of an adherent stromal layer (using a special substratum) and of an endothelial layer (in the presence of IL-2 and conditioned medium from the 5637 carcinoma cell line), respectively. We have recently described the establishment, under normal long-term culture conditions, of an adherent layer from human umbilical cord blood capable to support the 
proliferation of hematopoietic clonogenic cells (63; Alfonso ZZC, Forneck ED and Nardi NB, unpublished results). Different results probably reflect the varying experimental conditions employed.

The hematopoietic stroma is operationally defined by its ability to support hematopoiesis. This functional characteristic is more probably a result of interactions between the adherent cells and hematopoietic cells they make contact with, but although stromal layers can be developed by in vitro cultivation of different organs, only those derived from bone marrow were shown to support the proliferation of more primitive hematopoietic cells (64). Although stem cells adhere to stroma developed from other organs, their hematopoietic potential is not maintained. Additional factors - ECM interactions and cytokine stimulation - are important for the interaction of the hematopoietic cells with the stroma. Actually, the need for contact between elements of these two compartments is being questioned, and in culture systems in which progenitors are physically separated from the stroma layer by a microporous membrane (stroma noncontact culture), the LTC-IC has been shown to be maintained
(65). In LTC established under conditions favoring lymphoid development, however, contact between stem and stromal cells is required for maturation of hematopoietic cells (66). A more detailed study in which the composition of the stem cell compartment was analyzed suggested that different sets of stem cells may or may not require contact with stroma to proliferate and differentiate (67).

The investigation of the stromal compartment is also important for direct applications in human health. Abnormalities in the stromal compartment have been implicated as one of the possible mechanisms of aplastic anemia $(68,69)$, and may also be involved in the abnormal behavior of $\mathrm{Ph}+$ cells in chronic myeloid leukemia (68). The implications of a compatibility between transplanted hematopoietic cells and the receptor stroma has already been mentioned; the adequate in vitro expansion of hematopoietic cells for transplant or gene therapy purposes requires the establishment of stromal layers in various systems; and transduction of hematopoietic-supportive stromal cells with genes of interest is already being reported (70).

\section{References}

1. Ogawa M (1993). Differentiation and proliferation of hematopoietic stem cells. Blood, 81: 2844-2853.

2. Cumano A, Dieterlen-Lievre F \& Godin I (1996). Lymphoid potential, probed before circulation in mouse, is restricted to caudal intraembryonic splanchnopleura. Cell, 86: 907-916.

3. Medvinsky AL, Gan OI, Semenova ML \& Samoylina NL (1996). Development of day-8 colony-forming unit-spleen hematopoietic progenitors during early murine embryogenesis: spatial and temporal mapping. Blood, 87: 555-566.

4. Houssaint $E \&$ Hallet M-M (1988). Inability of adult circulating haemopoietic stem cells to sustain haemopoiesis in mouse fetal liver microenvironment. Immunology, 64: 463-467.
5. Slaper-Cortenbach I, Ploemacher R \& Lowenberg B (1987). Different stimulative effects of human bone marrow and fetal liver stromal cells on erythropoiesis in long-term culture. Blood, 69: 135-139.

6. Friedriclh C, Zausch E, Sugrue SP \& Gutierrez-Ramos JC (1996). Hematopoietic supportive functions of mouse bone marrow and fetal liver microenvironment: dissection of granulocyte, B-lymphocyte, and hematopoietic progenitor support at the stroma cell clone level. Blood, 87: 4595-4606.

7. Till JE \& McCulloch EA (1961). A direct measurement of the radiation sensitivity of normal mouse bone marrow cells. Radiation Research, 14: 213-218.

8. Orlic D \& Bodine DM (1994). What defines a pluripotent hematopoietic stem cell (PHSC): will the real PHSC please stand up! Blood, 84: 3991-3994.

9. Scott MA \& Gordon MY (1995). In search of the hemopoietic stem cell. British J ournal of Haematology, 90: 738-743.

10. Lord BI \& Dexter TM (1995). Which are the hematopoietic stem cells? (or: Don't debunk the history!). Experimental Hematology, 23: 1237-1241.

11. Lansdorp PM (1995). Developmental changes in the function of hematopoietic stem cells. Experimental Hematology, 23: 187-191.

12. Morrison SJ , Uchida N \& Weissman IL (1995). The biology of hematopoietic stem cells. Annual Review of Cell Development Biology, 11: 35-71.

13. Keller G, Wall C, Fong AZ, Hawley TS \& Hawley RG (1998). Overexpression of 
HOXI 1 leads to the immortalization of embryonic precursors with both primitive and definitive hematopoietic potential. Blood, 92: 877-887.

14. Ogden DA \& Micklem HS (1976). The fate of serially transplanted bone marrow cell populations from young and old donors. Transplantation, 22: 287-293.

15. Hayflick L (1965). The limited in vitro lifetime of human diploid cell strains. Experimental Cell Research, 37: 614-636.

16. Metcalf D \& Moore MAS (1971). Haematopoietic cells. In: Neuberger A \& Tatum EL (Editors), Frontiers of Biology. Vol. 24. North-Holland Publishing Company, Amsterdam.

17. Namikawa $R$, Weilbaeeher $\mathrm{KN}$, Kaneshima H, Yee EJ \& McCune J M (1990). Long-term human hematopoiesis in the SCID-hu mouse. J ournal of Experimental Medicine, 172: 1055-1063.

18. Larochelle A, Vormoor J, Hanenberg $\mathrm{H}$, Wang J CY, Bhatia M, L'apidot T, Moritz T, Mucdoch B, Xiao XL, Kato I, Williams DA \& Dick JE (1996). Identification of primitive human hematopoietic cells capable of repopulating NODISCID mouse bone marrow: Implications for gene therapy. Natural Medicine, 2: 1329-1337.

19. Bhatia M, Wang J CY, Kapp U, Bonnet D \& Dick J E (1997). Purification of primitive human hematopoietic cells capable of repopulating immune-deficient mice. Proceedings of the National Academy of Sciences, USA, 94: 5320-5325.

20. COPE, Cytokines Online Pathfinder Encyclopaedia (Horst Ibelgaufts' Hypertext Information Universe of Cytokines Version 2.1) (May 1998). http:// bioinfo.weizmann.ac.il/cgi-bin/cope/ cope.pl

21. Messner HA (1995). Assessment and characterization of hemopoietic stem cells. Stem Cells, 13 (Suppl 3): 13-18.

22. Metcalf D (1997). Hemopoietic Colonies. In Vitro Cloning of Normal and Leukemic Cells. Springer-Verlag, Berlin, Heidelberg.

23. Gordon MY, Lewis J L, Grand FH, Marley SB \& Goldman J M (1996). Phenotype and progeny of primitive adherent human hematopoietic progenitors. Leukemia, 10: 1347-1353.

24. Clark SC \& Kamen R (1987). The human hematopoietic colony-stimulating factors. Science, 236: 1229-1237.

25. Dexter TM \& Lajtha LG (1974). Proliferation of hemopoietic stem cells in vitro. British J ournal of Haematology, 28: 525530.

26. Gartner S \& Kaplan HS (1980). Long term culture of human bone marrow cells. Pro- ceedings of the National Academy of Sciences, USA, 77: 4756-4759.

27. Coulombel L, Eaves AC \& Eaves CJ (1983). Enzymatic treatment of long-term human marrow cultures reveals the preferential location of primitive hemopoietic progenitors in the adherent layer. Blood, 62: 291-297.

28. Whitlock CA, Robertson D \& Witte ON (1984). Murine B cell lymphopoiesis in long term cultures. J ournal of Immunological Methods, 67: 353-369.

29. Weilbaecher $K$, Weissman I, Blume $K \&$ Heimfeld S (1991). Culture of phenotypically defined hematopoietic stem cells and other progenitors at limiting dilution on Dexter monolayers. Blood, 78: 945952.

30. Weaver A, Ryder WD \& Testa NG (1997). Measurement of long-term culture initiating cells (LTC-ICS) using limiting dilution: comparison of endpoints and stromal support. Experimental Hematology, 25: 13331338.

31. Hao Q-L, Thiemann FT, Petersen D, Smogorzewska EM \& Crooks GM (1996). Extended long-term culture reveals a highly quiescent and primitive human hematopoietic progenitor population. Blood, 88: 3306-3313.

32. Eaves CJ, Cashman JD \& Eaves AC (1991). Methodology of long-term culture of human hemopoietic cells. Joumal of Tissue Culture Methods, 13: 55-62.

33. Dexter TM, Allen TD \& Lajtha LG (1976). Conditions controlling the proliferation of haemopoietic stem cells in vitro. J ournal of Cell Physiology, 91: 335-344.

34. Tavassoli M (1984). Marrow adipose cells and hemopoiesis: an interpretative review. Experimental Hematology, 12: 139146.

35. Fernández M \& Minguell JJ (1996). The role of collagen in hematopoiesis. Brazilian J ournal of Medical and Biological Research, 29: 1201-1207.

36. Stephan RP, Reilly CR \& Witte PL (1998). Impaired ability of bone marrow stromal cells to support B-lymphopoiesis with age. Blood, 91: 7-88.

37. Kameoka J, Yanai N \& Obinata M (1995). Bone marrow stromal cells selectively stimulate the rapid expansion of lineagerestricted myeloid progenitors. J ournal of Cell Physiology, 164: 55-64.

38. Gauthier L, Fougereau $M$ \& Tonelle $C$ (1998). Construction of temperature and $\mathrm{Zn}$-dependent human stromal cell lines that amplify hematopoietic precursors from cord blood CD34+ cells. Experimental Hematology, 26: 534-540.
39. Aiuti A, Friedrich C, Sieff CA \& GutierrezRamos J C (1998). Identification of distinct elements of the stromal microenvironment that control human hematopoietic stem/progenitor cell growth and differentiation. Experimental Hematology, 26: 143-157.

40. Sitnicka $E$, Wang QR, Tsai $S \&$ Wolf NS (1995). Support versus inhibition of hematopoiesis by two characterized stromal cell types. Stem Cells, 13: 655-665.

41. Riley GP \& Gordon MY (1987). Characterization of cultured stromal layers derived from fetal and adult hematopoietic tissues. Experimental Hematology, 15: 7884.

42. Van Den Heuvel R, Schoeters G, Leppens H \& Vanderborght O (1991). Stromal cells in long-term cultures of liver, spleen and bone marrow at different developmental stages have different capabilities to maintain M-CSF proliferation. Experimental Hematology, 19: 115-121.

43. Roy $\vee \&$ Verfaillie CM (1997). Soluble factor(s) produced by adult bone marrow stroma inhibit in vitro proliferation and differentiation of fetal liver BFU-E by inducing apoptosis. J ournal of Clinical Investigation, 100: 912-920.

44. Owen M \& Friedenstein AJ (1988). Stromal stem cells: marrow-derived osteogenic precursors. Ciba Foundation Symposium, 136: 42-60.

45. Prockop DJ (1997). Marrow stromal cells as stem cells for nonhematopoietic tissues. Science, 276: 71-74.

46. Simmons PJ , Przeipiorka D, Thomas ED \& Torok-Storb B (1987). Host origin of marrow stromal cells following allogeneic bone marrow transplantation. Nature, 328: 429-432.

47. Laver J , J hanvar SC, Oreilly RJ \& CastroMalaspina $H$ (1987). Host origin of human hematopoietic microenvironment following bone marrow transplantation. Blood, 70: 1966-1968.

48. Tanaka J, Kasai M, Imamura M, Masauzi $\mathrm{N}$, Ohizumi $\mathrm{H}$, Matsuura A, Morii $\mathrm{K}$, Kiyama Y, Naohara T \& Saitoh M (1994). Evaluation of mixed chimaerism and origin of bone marrow derived fibroblastoid cells after allogeneic bone marrow transplantation. British J ournal of Haematology, 86: 436-438.

49. Keating $A$, Singer J W, Killen PD, Striker GE, Salo AC, Sanders J, Thomas ED, Thoming D \& Fialkow PJ (1982). Donor origin of the in vitro microenvironment after marrow transplantation in man. $\mathrm{Na}$ ture, 298: 280-283.

50. Almeida-Porada GD, Hoffman R, Manalo 
P, Gianni AM \& Zanjani ED (1996). Detection of human cells in human/sheep chimeric lambs with in vitro human stromaforming potential. Experimental Hematology, 24: 482-487.

51. Pereira RF, Halford KW, O'Hara MD, Leeper DB, Sokolov BP, Pollard MD, Bagasra O \& Prockop DJ (1995). Cultured adherent cells from marrow can serve as long-lasting precursor cells for bone, cartilage, and lung in irradiated mice. Proceedings of the National Academy of Sciences, USA, 92: 4857-4861.

52. Ferrari G, Cusella-De Angelis G, Coletta M, Paolucci E, Stornaiuolo A, Cossu G \& Mavilio $F$ (1998). Muscle regeneration by bone marrow-derived myogenic progenitors. Science, 279: 1528-1530.

53. Sutkowski N, Kuo ML, Amenta PS, Dougherty J P \& Ron Y (1995). A peripheral blood-derived monolayer supports longterm cultures of human on CD4+ and CD8+ T lymphocytes. Blood, 85: 32133222.

54. Shi Q, Rafii S, Wu MH, Wijelath ES, Yu C, Ishida A, Fujita $Y$, Kothari S, Mohle R, Sauvage LR, Moore MA, Storb RF \& Hammond WP (1998). Evidence for circulating bone marrow-derived endothelial cells. Blood, 92: 362-367.

55. Fernandez M, Simon V, Herrera G, Cao C, Del Favero H \& Minguell J J (1997). Detection of stromal cells in peripheral blood progenitor cell collections from breast cancer patients. Bone Marrow Transplantation, 20: 265-271.

56. Ojeda-Uribe $M$, Brunot $A$, Lenat $A \&$ Legros M (1993). Failure to detect spindleshaped fibroblastoid cell progenitors in PBPC collections. Acta Haematologica, 90: 139-143.
57. Lazarus HM, Haynesworth SE, Gerson SL \& Caplan Al (1997). Human bone marrowderived mesenchymal (stromal) progenitor cells (MPCs) cannot be recovered from peripheral blood progenitor cell collections. J ournal of Hematotherapy, 6: 447455.

58. Mayani H, Gutierrez-Rodriguez $M$, Espinoza L, Lopez-Chalini E, HuertaZepeda A, Flores E, Sanchez-Valle E, Luna-Bautista F, Valencia I \& Ramirez OT (1998). Kinetics of hematopoiesis in Dexter-type long-term cultures established from human umbilical cord blood cells. Stem Cells, 16: 127-135.

59. Ye Z-Q, Burkholder J K, Qiu P, Schultz J C, Shahidi NT \& Yang N-S (1994). Establishment of an adherent cell feeder layer from human umbilical cord blood for support of long-term hematopoietic progenitor cell growth. Proceedings of the National Academy of Sciences, USA, 91: 1214012144.

60. Nieda M, Nicol A, Denning-Kendall $P$, Sweetenham J, Bradley B \& Hows J (1997). Endothelial cell precursors are normal components of human umbilical cord blood. British J ournal of Haematology, 98: 775-777.

61. Prindull G, Ben-Ishay Z, Ebell W, Bergholz M, Dirk T \& Prindull B (1987). CFU-F circulating in cord blood. Blut, 54: 351-359.

62. Hows J M, Bradley BA, Marsh J CW, Luft T, Coutinho L, Testa NG \& Dexter TM (1992). Growth of human umbilical-cord blood in longterm haemopoietic cultures. Lancet, 340: 73-76.

63. Silva ZZA, Forneck ED \& Nardi NB (1996). Establishment of adherent cell layer from umbilical cord blood. Blood, 88: 130b (Abstract).
64. Rios M \& Williams DA (1990). Systematic analysis of the ability of stromal cell lines derived from different murine adult tissues to support maintenance of hematopoietic stem cells in vitro. J ournal of Cell Physiology, 145: 434-443.

65. Miller J S, McCullar V \& Verfaillie CM (1998). Ex vivo culture of CD34+/Lin-/DR. cells in stroma-derived soluble factors, interleukin-3, and macrophage inflammatory protein-lo maintains not only myeloid but also lymphoid progenitors in a novel switch culture assay. Blood, 91: 45164522.

66. Stephan RF, Reilly CR \& Witte PL (1998). Impaired ability of bone marrow stromal cells to support B-lymphopoiesis with age. Blood, 91: 75-88.

67. Ohkawara J I, Ikebuchi K, Fujihara M, Sato $\mathrm{N}$, Hirayama F, Yamaguchi M, Mori KJ \& Sekiguchi S (1998). Culture system for extensive production of CD19+IgM + cells by human cord blood CD34+ progenitors. Leukemia, 12: 764-771.

68. Gordon MY (1994). Physiology and function of the haemopoietic microenvironment. British J ournal of Haematology, 86: 241-242.

69. Kojima S (1998). Hematopoietic growth factors and marrow stroma in aplastic anemia. International J ournal of Hematology, 68: 19-28.

70. Bulabois CE, Yerly-Motta V, Mortensen BT, Fixe P, Remy-Martin J P, Herve P, Tiberghien P \& Charbord P (1998). Retroviral-mediated marker gene transfer in hematopoiesis-supportive marrow stromal cells. J ournal of Hematotherapy, 7: 225-239. 